\title{
ATELELE
}

\section{Avaliação da demanda hídrica por pivôs centrais e agroindústrias na Alta Bacia do Ribeirão Santo Inácio- Orizona/GO}

\author{
Water demand assessment by central pivots and \\ agroindustries in Ribeirão Santo Inácio High Basin - \\ Orizona/GO
}

\section{Evaluación de la demanda de agua por pivotes centrales y agroindustrias en la Alta Cuenca de Ribeirão Santo Inácio - Orizona/GO}

\author{
Lorena de Castro Rodrigues \\ Universidade Federal de Goiás \\ rodrigues.lorenac@gmail.com \\ Maximiliano Bayer \\ Universidade Federal de Goiás \\ maxibayer@yahoo.com.ar
}

\begin{abstract}
Resumo
A atividade agrícola é a principal responsável pelo uso consuntivo da água seguida pela atividade industrial. $\mathrm{O}$ agrohidronegócio ganha espaço à medida que a demanda por alimentos no mundo aumenta. Essa realidade é presente na Alta Bacia do Ribeirão Santo Inácio, localizada no município de Orizona (GO), onde ocorre uma dependência mútua entre atividade agrícola irrigada e atividade industrial. Os mapas temáticos deste estudo auxiliam a compreender a dinâmica da microbacia apresentando as características físicas do ambiente como a predominância de latossolos e baixa declividade do relevo nas proximidades dos cursos d'água, o que propicia a intensa atividade agrícola irrigada por pivô central. A projeção do total de água captada pelos pivôs centrais foi realizada a partir do cálculo de subtração da precipitação e a evapotranspiração da cultura plantada multiplicado pelo tamanho da área de cada pivô central. Conclui-se que se que nos meses do período de estiagem o déficit hídrico chega a 1.092 metros cúbicos por hora, implicando no consumo hídrico das agroindústrias que captam água a jusante do Ribeirão Santo Inácio.
\end{abstract}

Palavras-chave: Pivô central; Atividade industrial; Água; déficit hídrico. 


\begin{abstract}
The agricultural activity is mainly responsible for water consumption use followed by industrial activity. Agro-business grows as the demand for food in the world increases. This reality is in the upper Ribeirão Santo Inácio Basin, a city named Orizona (GO), where there is a mutual dependence between irrigated agricultural activity and industrial activity. The thematic maps of this study help to understand the micro basin dynamics showing physical environment characteristics such as latosols predominance and relief low slope near the watercourses, which provides heavy agricultural activity irrigated by central pivot. The total water projection captured by central pivots was performed from the precipitation subtraction calculation and the planted crop evapotranspiration multiplied by the area size of each central pivot. It is concluded that in drought month's period the water deficit reaches 1,092 cubic meters per hour, increasing the water consumption of agro industries that capture water downstream from Ribeirão Santo Inácio.
\end{abstract}

Keywords: Central pivot; Industrial activity; Water; Water deficit.

\begin{abstract}
Resumen
La actividad agrícola es la principal responsable del uso consuntivo del agua seguido de la actividad industrial. La agroinrretición gana espacio a medida que aumenta la demanda de alimentos en el mundo. Esta realidad está presente en la cuenca alta del Ribeirão Santo Inácio, ubicada en el municipio de Orizona (GO), donde existe una dependencia mutua entre la actividad agrícola irrigada y la actividad industrial. Los mapas temáticos de este estudio ayudan a entender la dinámica de la Microcuenca presentando las características físicas del medio ambiente como predominio de los latosoles y baja pendiente del relieve en las proximidades de las vías fluviales, lo que proporciona la intensa Actividad agrícola regada por pivote central. La proyección del agua total capturada por los pivotes centrales se realizó calculando la resta de la precipitación y la evapotranspiración del cultivo plantado multiplicado por el tamaño del área de cada pivote central. Se concluye que, en los meses del período de sequía, el déficit hídrico alcanza los 1.092 metros cúbicos por hora, lo que implica el consumo de agua de las agroindustrias que capturan aguas abajo del Ribeirão Santo Inácio.
\end{abstract}

Palabras clave: Pivote central; Actividad industrial; Agua; Déficit hídrico.

\title{
Introdução
}

A água é um bem natural e limitado. Segundo Poleto (2014), os conflitos pela sua utilização estão se tornando rotineiros devido ao crescimento demográfico e econômico, alterando a visão cultural de que ela é um recurso natural infinito e abundante.

O Brasil possui a maior reserva de água doce do mundo, somando $12 \%$ do total distribuídos em mananciais e rede de lençóis freáticos. Apesar disso, essa reserva encontra-se mal distribuída pelo território nacional causando desequilíbrio nos balanços hídricos regionais, com excesso de água na região Norte onde existe um contingente menor de pessoas e uma crescente escassez nas regiões de maior população e desenvolvimento industrial e agrícola (ANA, 2017a).

Segundo Teodoro et al. (2007) a bacia hidrográfica é um sistema aberto, no qual seus elementos mantêm relações dinâmicas entre os componentes físicos, biológicos e 
socioeconômicos. O uso e ocupação do solo, associado às características da declividade e da cobertura vegetal, são fatores significativos que auxiliam a tomada de decisão e o manejo da bacia hidrográfica considerando que essas alterações influenciam a precipitação efetiva, o escoamento superficial e o fluxo da água no solo, dentre outros. Adicionalmente, Lima (2008) comenta que, para avaliar o efeito que teria qualquer perturbação em uma bacia hidrográfica, é necessário antes conhecer bem as características hidrológicas do ecossistema natural.

Segundo Bouguerra (2004), a água tem sido discutida nos mais diversos âmbitos nacionais e mundiais sendo considerada o petróleo do século XXI, tratada mais como uma mercadoria com o intuito de gerar lucro. Para ambientalistas ela é um bem finito e essencial à vida, havendo a necessidade de uma gestão eficiente a fim de controlar e garantir a qualidade e a quantidade de água e evitar conflitos nos seus diversos usos múltiplos.

Todavia, para Cooley (1984), por mais que seja necessário um plano para a distribuição racional e igualitária da água, as questões relacionadas à mesma são agravadas por tensões políticas e econômicas, sobretudo quando se considera a vantagem ou benefício individual sob a forma maior de consumo.

Nesse contexto, este estudo avalia o consumo total de água captada pelas agroindústrias e pela agricultura irrigada na Alta Bacia do Ribeirão Santo Inácio, localizada no município de Orizona (GO) a partir de uma projeção anual das culturas plantadas em cada pivô central e apresenta as características físicas que influenciam sua dinâmica hidrológica.

\section{Contextualização do conflito pela utilização da água na Alta Bacia do Ribeirão Santo Inácio}

Os primeiros pivôs instalados no município de Orizona, localizada no Sudeste goiano, remontam a década de 1990. Em áreas previamente utilizadas para cultura de grãos, em especial a soja, os pivôs foram instalados para permitir maximizar o uso das lavouras também nos meses secos do ano. Além da soja, o cultivo do feijão em áreas irrigadas no centro-oeste atraiu muitos agricultores de maior escala, para conseguir fornecer o grão em época da entre safra da produção no sul do Brasil. Nessa mesma época houve o início da produção de atomatados pela indústria Arisco na capital Goiânia, com forte crescimento da linha de produtos, atendendo o Brasil inteiro e muitos países no exterior. A mesma, se tornou a principal marca de referência em atomatados, em especial o extrato de tomate. Isto fez com que crescesse em Goiás a produção de tomate para processamento industrial.

Dessa forma, a partir do final de 1990, os primeiros agricultores começaram a cultivar tomate industrial em áreas de pivô central e agroindústrias se instalaram no estado de Goiás, com foco em processamento e conservas de vegetais. Atualmente, estão em operação mais de (10) dez agroindústrias de atomatados e vegetais em conservas no Sudeste goiano em que as produções dos pivôs centrais são direcionadas, fomentando 
uma produção anual de mais de 10 mil hectares de tomate industrial, além de mais de 30 mil hectares de milho doce, também produzido sob irrigação de pivô central.

A Alta Bacia do Ribeirão Santo Inácio se enquadra nesse cenário em que atualmente abrange ao longo dos canais de drenagem nove (9) pivôs centrais a montante e duas agroindústrias a jusante, as quais desempenham importante influência econômica para o município. Todavia, torna-se importante analisar a Alta Bacia do Ribeirão Santo Inácio, pois além de ser uma área relativamente pequena $\left(95,7 \mathrm{~km}^{2}\right)$ onde é possível ter o controle do consumo da água, essa área tem sido cenário de conflitos entre seus usuários, devido à demanda ser maior que a quantidade de água disponível no período de estiagem.

Segundo documentos oficiais disponibilizados pela indústria e prefeitura local (Ofício CO-GG nº 003/2018 e PMO-GP n 699/2017), houve paralisação na produção industrial por falta de água por mais de 75 horas somando as interrupções entre os meses de agosto a outubro de 2017. A paralisação da indústria acarreta ao não recebimento da matéria-prima, gerando então, prejuízos tanto para a indústria quanto para os agricultores.

Nos meses de estiagem associado ao período de florescimento das culturas, mesmo com as barragens utilizadas para captação de água dos pivôs-centrais, o nível de água se torna crítico e o nível d'água mínimo operacional (nível mínimo necessário para a operação, normalmente este nível é definido acima do limite superior da estrutura de tomada d'água de modo a evitar a formação de vórtices nesta entra e evitar o ingresso de ar no conduto forçado) fica comprometido o que leva alguns produtores bloquearem a vazão mínima de água a jusante da barragem.

\section{O consumo de água pela agricultura}

O consumo elevado de água na agricultura que corresponde a cerca de $72 \%$ do uso no Brasil juntamente com a poluição dos lençóis freáticos e do solo, agrava frontalmente a crise hídrica (OLIVEIRA e ASSUNÇÃO, 2013). Pelo fato de a irrigação ser a principal concorrente pelo uso da água disponível numa determinada unidade hidrográfica de planejamento, deve-se estimular um manejo racional da irrigação e a otimização dos equipamentos utilizados, com a finalidade de tornar o uso da água o mais eficiente possível.

Segundo Mendonça (2010), o agrohidronegócio pode ser entendido como sendo uma ramificação do agronegócio que se apropria da água para maximizar os lucros e, no caso do pivô central, minimizar os prejuízos, principalmente aquele decorrente de estiagens ou secas prolongadas. $\mathrm{O}$ uso da água para agricultura irrigada e para geração de energia, são algumas das principais causas que conduz conflitos, pois elevam o consumo de água em níveis exorbitantes. Além disso, o agrohidronegócio promove a ocupação e redução dos espaços com cobertura vegetal natural, imprescindíveis para a manutenção do ciclo hidrológico, dos mananciais e da biodiversidade. 
O déficit hídrico em áreas agrícolas ocorre quando a precipitação é inferior a evapotranspiração da respectiva cultura plantada, prejudicando seu crescimento (SANTOS e CARLESSO, 1998). Por isso, a utilização de pivôs centrais como método de irrigação agrícola tem crescimento de forma acelerada, pois mesmo nos períodos de déficit hídrico, é possível a colheita na entressafra, além de ampliar o período de produção e de exploração agrícola.

A agricultura irrigada no Brasil é associada a um elevado nível tecnológico, porém, é consenso que ainda é praticada de forma inadequada com grandes desperdícios. Marouelli et al. (2011, p. 159) explica que:

Estima-se que de toda a água captada para fins de irrigação as perdas podem chegar até 50\%: tal problema ocorre em razão de três fatores principais: a) diminuta utilização de critérios técnicos de manejo de água na maioria das áreas irrigadas; b) informações escassas e incompletas de parâmetros para manejo de água; c) uso de sistemas de irrigação com baixa eficiência de aplicação de água.

O manejo apropriado da irrigação não pode ser considerado uma etapa independente dentro do processo de produção agrícola, tendo, por um lado, o compromisso com a produtividade da cultura explorada e, por outro, o uso eficiente da água, promovendo a conservação do meio ambiente (MARTINS, 2017).

Cada cultura necessita de uma quantidade de água, e em cada fase de desenvolvimento da mesma cultura essa quantidade também varia, conforme mostra a figura 1. A irrigação visa suplementar o que a planta necessita, ou seja, complementa o que é fornecido pelas demais fontes (solo e chuva). Segundo a ANA (2017a), o balanço hidrológico simplifica os processos que ocorrem na agricultura irrigada relacionada ao ciclo hidrológico, baseando-se na disponibilidade de informações climáticas e nas características das culturas e dos sistemas de irrigação. Os dados climáticos informam qual o suprimento de água da chuva para as plantas e qual a evapotranspiração potencial de uma região.

Segundo Martins (2017), no estado de Goiás no ano de 2016, a prática da agricultura irrigada por pivô central foi registrada em 151 dos 246 municípios. Isso significa que em apenas 95 municípios esse sistema de manejo agrícola ainda não se faz presente. Segundo a ANA (2017b), o Centro-Oeste foi a região de maior expansão agrícola nos últimos 20 anos, quadruplicando a área para 1,2 milhões de hectares, e o estado de Goiás foi responsável pela maior parte desse crescimento, sextuplicando a área irrigada entre 1996 e 2015, representando 18\% do total da área irrigada por pivô-central no Brasil. 


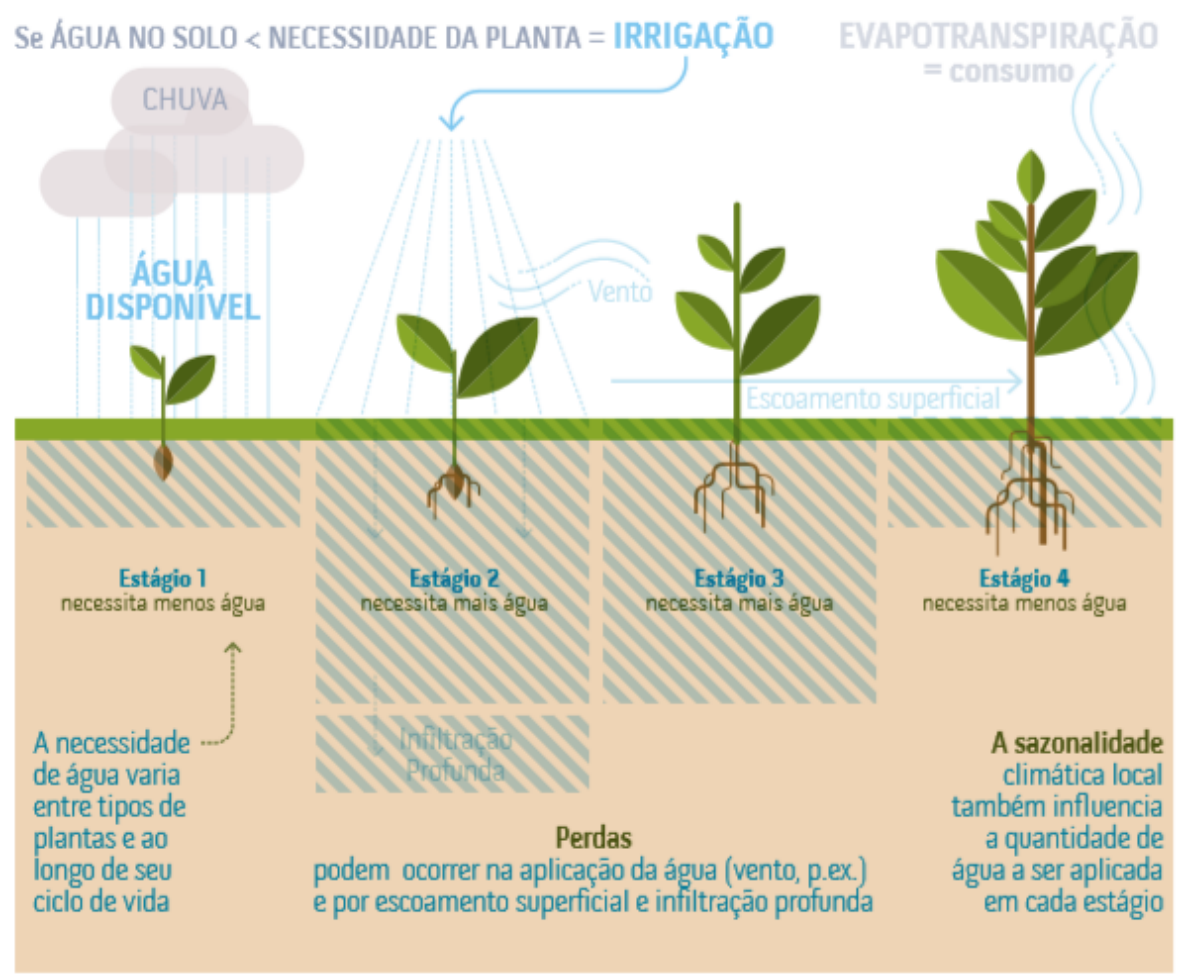

Figura 01: Representação esquemática dos processos relacionados à irrigação.

Fonte: ANA (2017).

Além disso, as projeções da ANA para expansão de área irrigada para o ano de 2030, considerando as classes de aptidão solo-relevo, apresenta a região Centro-Oeste com a maior concentração de áreas de alta aptidão com efetivo potencial irrigável de $43,1 \%$, sendo Goiás o segundo maior estado do Brasil com maior potencial irrigável com aumento de cerca de $12,8 \%$ ou 1,4 milhões de hectares adicionais de área irrigável, ficando atrás apenas do estado de São Paulo que representa 20,4\% da concentração das áreas de efetivo potencial irrigável (ANA, 2017b). A demanda média anual por microbacia para pivôs centrais no Brasil (não contabilizando as áreas de arroz inundado e cana-de-acúcar) em 2015 foi de 177 mil 1/s e estima-se um salto para 361 mil 1/s (um aumento de $104 \%$ ). No estado de Goiás, a média anual de retirada de água por pivôs centrais foi de 33,8 m³/s em 2015 e estima-se um salto de 69,5\% para o ano de 2030 .

\section{Metodologia}

Os procedimentos metodológicos para este trabalho partiram do levantamento de dados cartográficos, bibliográficos e pesquisas de campo na área de estudo. 
A bacia foi delimitada no software ArcGIS, ferramenta Hydrology aplicada a imagens do satélite ALOS. O mapa de uso e cobertura do solo foi gerado a partir de uma atualização do Terraclass em que apresenta um mapeamento com imagens Landsat de resolução espacial de 30 metros para todo o bioma Cerrado. As informações do Terraclass foram atualizadas para o ano de 2017 e para a resolução de 10 metros por meio de técnica de inspeção visual de imagem utilizando imagens Sentinel-2. As áreas que houve alterações de usos foram editadas para terem o uso correspondente do ano em questão.

Os dados de hidrografia foram delimitados manualmente pela plataforma Google Earth Pro, para garantir maior nível de detalhe. O mapa de tipos do solo foi feito a partir de dados gerais do banco de dados do Radam e refinado conforme a declividade do relevo.

Os dados de Áreas de Preservação Permanente (APPs) foram gerados respeitando a largura mínima estipulada pelo código florestal:

"I - As faixas marginais de qualquer curso d'água natural perene e intermitente, excluídos os efêmeros, desde a borda da calha do leito regular, em largura mínima de:

a) 30 (trinta) metros, para os cursos d'água de menos de 10 (dez) metros de largura;

b) 50 (cinquenta) metros, para os cursos d'água que tenham de 10 (dez) a 50 (cinquenta) metros de largura;

c) 100 (cem) metros, para os cursos d'água que tenham de 50 (cinquenta) a 200 (duzentos) metros de largura;

d) 200 (duzentos) metros, para os cursos d'água que tenham de 200 (duzentos) a 600 (seiscentos) metros de largura;

e) 500 (quinhentos) metros, para os cursos d'água que tenham largura superior a 600 (seiscentos) metros."

Para gerar os dados de situação das APPs, os dados de larguras das áreas de preservação foram interseccionados com os dados de uso e cobertura do solo do ano de 2017, e depois foram inspecionados criteriosamente na plataforma Google Earth Pro, para este dado ser os mais próximos do real.

Para realizar a projeção do consumo hídrico das agroindústrias e da agricultura irrigada foram coletados dados a partir de pesquisa em campo para identificar quais culturas são plantadas anualmente por cada pivô e quais matérias-primas são utilizadas nas indústrias.

A demanda de água para irrigação, conforme é exemplificado no Atlas de irrigação da Agência Nacional das Águas (ANA, 2017b), foi determinada em metros cúbicos ao mês na área de cada pivô. Após identificar as culturas e o período em que são plantadas, foi realizado o balanço hídrico entre precipitação (entrada de água) e a evapotranspiração (saída de água). Para obter a evapotranspiração da cultura (ETc) foi realizado a multiplicação da evapotranspiração de referência (Eto) com o coeficiente da cultura $(\mathrm{Kc})$ que são valores padrão determinados pela Organização das Nações Unidas 
para a Alimentação e a Agricultura (FAO, 2018). A demanda de ETc varia de acordo com o tipo de cultura cultivada, bem como o estágio de desenvolvimento fenológico da mesma. Após essa etapa, foi feita a subtração entre a precipitação média mensal $(\mathrm{mm})$ e a ETc mensal (mm). O resultado da subtração acima multiplicado pela área do pivô irá gerar o balanço hídrico da área, considerando que um milímetro de chuva em um metro quadrado corresponde a um litro de água. Foram ainda subtraídos 30\% do valor total considerando as perdas por pivô central para então gerar o total de água a ser captado.

Para os valores de precipitação foi realizado uma média dos dados em milímetros disponíveis no site do Inmet entre os anos de 1980 e 2010. Os valores do consumo hídrico agroindustrial foram fornecidos pelas mesmas.

\section{Área de estudo}

A Alta Bacia do Ribeirão Santo Inácio está situada no município de Orizona, no Sudeste do estado de Goiás, entre as latitudes $16^{\circ} 52^{\prime \prime}$ e $17^{\circ} 00^{\prime}$ sul e longitudes $48^{\circ} 24^{\prime \prime}$ e $48^{\circ} 16^{\prime \prime}$ oeste de Greenwich e possui $95,7 \mathrm{~km}^{2}$ de área. Inserido na sub-bacia do Rio Corumbá, o Ribeirão Santo Inácio é um afluente do Ribeirão Santana que drena para o Rio Piracanjuba (figura 2). Na área de estudo, o Ribeirão Santo Inácio abastece 458,5 hectares de área irrigada e duas agroindústrias, além de fornecer água para uso doméstico e agropecuária.

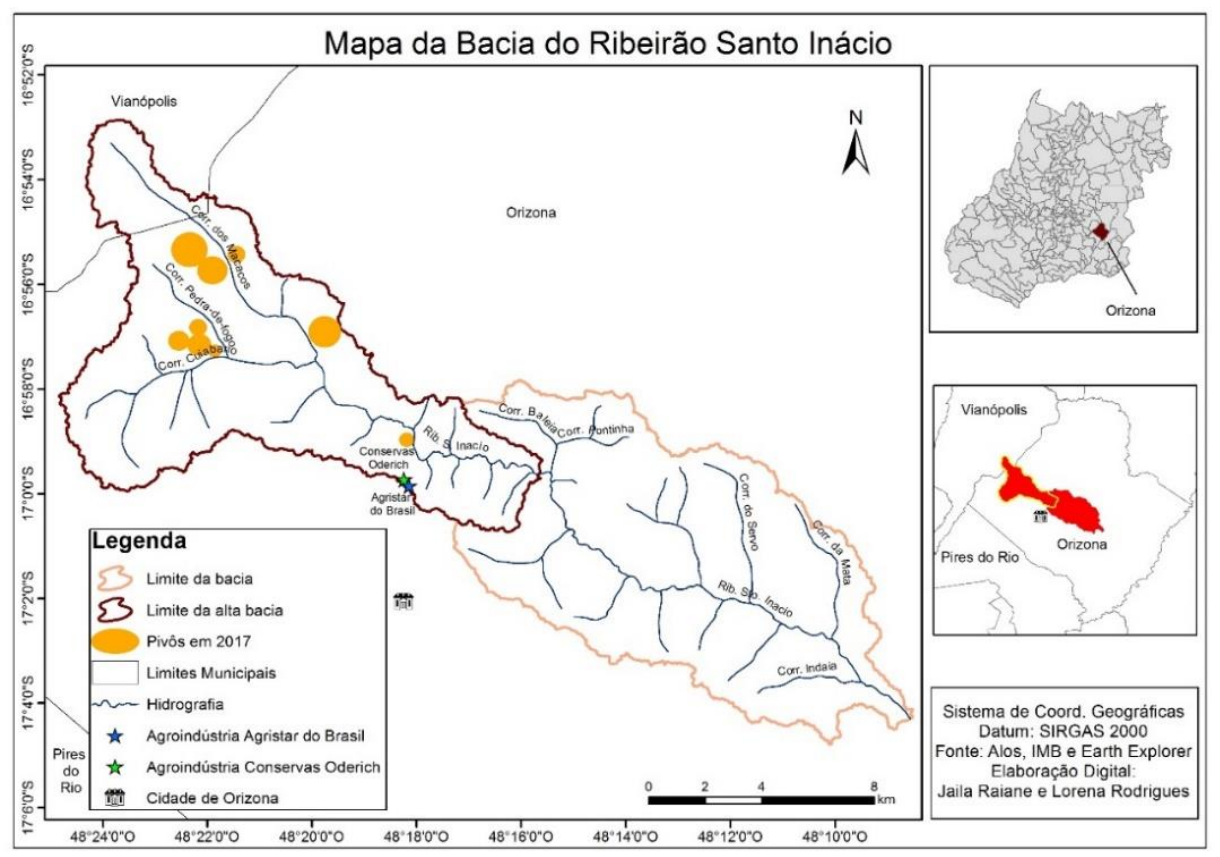

Figura 02: Mapa de localização da Bacia do Ribeirão Santo Inácio.

Fonte: ALOS, IMB (2017) e Earth Explorer. 


\section{Caracterização física da Alta Bacia do Ribeirão Santo Inácio}

O planejamento do uso e a ocupação do solo são condicionados pelas características naturais de cada bacia hidrográfica. Na maior parte da área da bacia predominam latossolos de textura argilosa. Entretanto, o cambissolo aparece numa pequena porção a oeste da área a qual é destinada para o uso de pastagens, por ser este considerado um solo jovem e pouco profundo sendo inviável para a agricultura.

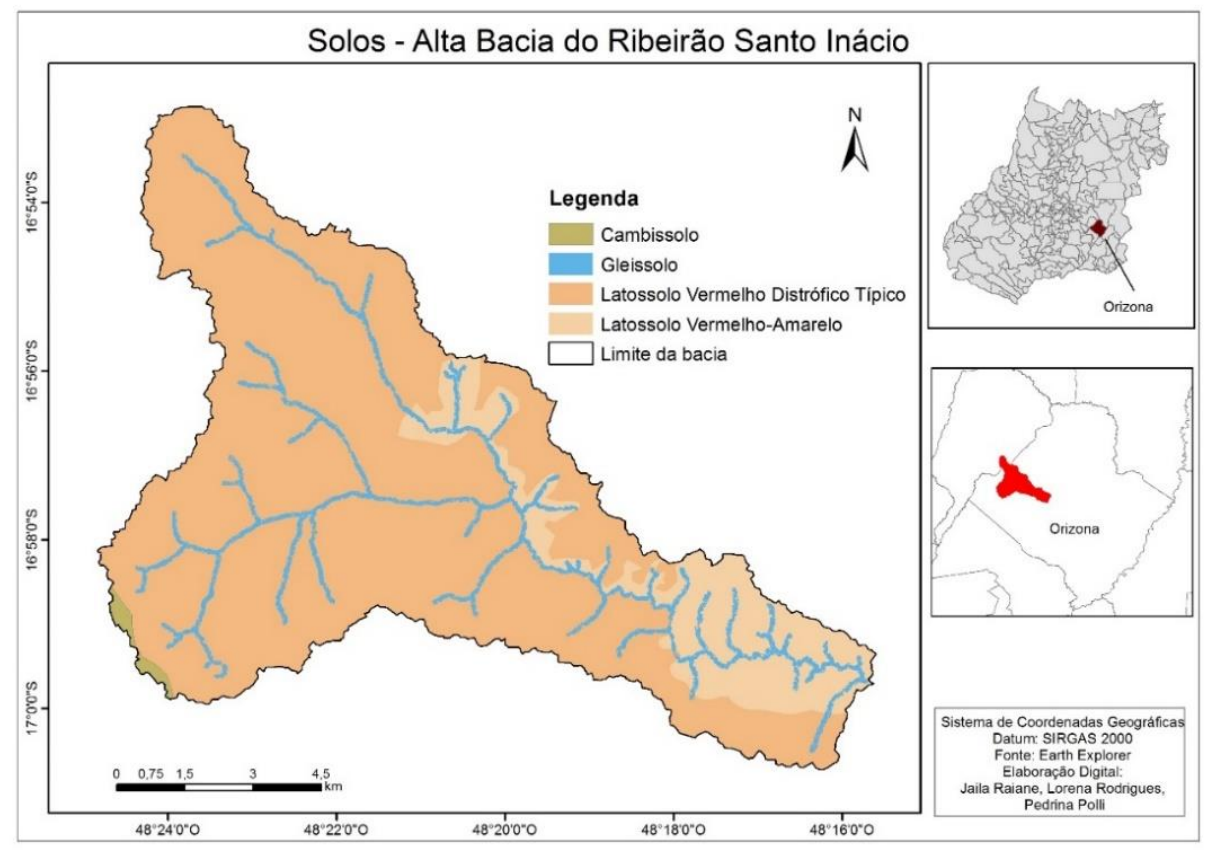

Figura 03: Mapa dos tipos de solo na Alta Bacia do Ribeirão Santo Inácio.

O Latossolo Vermelho Distrófico Típico está presente na maior área da microbacia seguido pelo Latossolo Vermelho-Amarelo. São solos de textura argilosa e de média concentração de nutrientes e em sua maioria são destinados a agricultura após o manejo adequado com fertilizantes para a correção da sua acidez (EMBRAPA, 2006).

Nas proximidades da rede de drenagem identifica-se um gleissolo, caracterizado por material mineral com horizonte glei (acizentado) não apresentando horizonte vértico ou horizonte B com mudança textural significativa. Esse solo é resultante de processos de intensa redução de compostos de ferro em presença de matéria orgânica, com ou sem alternância de oxidação, por efeito de flutuação de nível do lençol freático, em condições de regime de excesso de umidade permanente ou periódico (EMBRAPA, 2006). 
A declividade da área foi baseada nos intervalos em porcentagem propostos por Ramalho Filho e Beek (1995) reduzindo-os a quatro classes principais, que são: 0 - $8 \%$ (plano), 8,1 - 20\% (suave ondulado), 20,1 - 35\% (ondulado), 35,1 - 45\% (forte ondulado). Os intervalos são definidos conforme o grau de limitação de uso do solo em função da susceptibilidade a erosão.

Ao analisarmos os dados obtidos para os dois mapas verificamos que, a maior parte de relevo está compartimentados em relevos planos e suavemente ondulados com altitudes que variam 169 metros da porção mais alta até o declive mínimo onde se encontram os canais de drenagem.

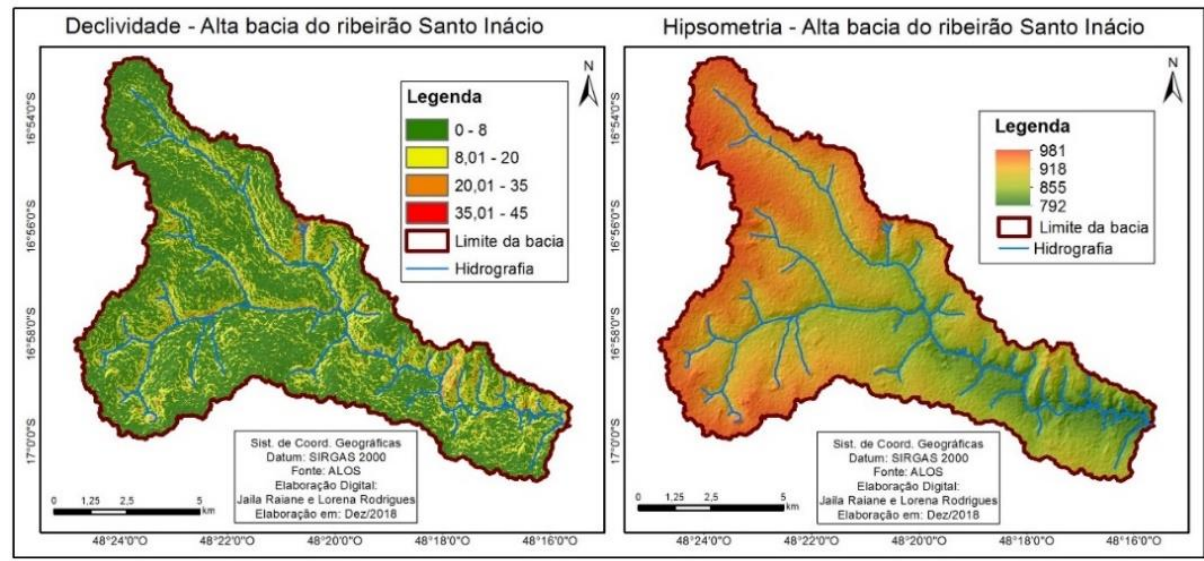

Figura 04: Mapas de declividade e hipsometria.

Conforme os resultados da tabela 01, o relevo plano ocupa cerca de $67,6 \%$ da área, o que representa impedimento nulo para mecanização agrícola e muito baixo risco de erosão; 30,1\% da área da bacia apresenta relevo suave ondulado o que representa um impedimento ligeiro à mecanização e pouca suscetibilidade à erosão; $1,9 \%$ da área possui um relevo ondulado o que representa um impedimento moderado à mecanização e suscetibilidade à erosão e apenas $0,4 \%$ apresenta relevo forte ondulado o que representa forte impedimento a mecanização agrícola e forte suscetibilidade à erosão.

Tabela 01: Classes de relevo e declividade na área da Alta Bacia do Ribeirão Santo Inácio

\begin{tabular}{c|c|c|c}
\hline Classe de relevo & Declividade (\%) & Área (\%) & Impedimento ou limitação \\
\hline Plano & $0-8$ & 67,6 & Nulo \\
\hline Suave ondulado & $8,1-20$ & 30,1 & Ligeiro \\
\hline Ondulado & $20,1-35$ & 1,9 & Moderado \\
\hline Forte ondulado & $35,1-45$ & 0,4 & Forte \\
\hline
\end{tabular}

Fonte: elaborado pelos autores com base em dados do satélite ALOS. 
Os relevos planos e suavemente ondulados, segundo Ramalho Filho e Beek (1995), são indicados para culturas anuais, com auxílio de práticas de conservação de solo. O relevo ondulado e forte ondulado são áreas com maior fragilidade a processos de erosão e recomenda-se a serem áreas de preservação e conservação ambiental, entretanto podem ser utilizados para pecuária e silvicultura.

Por se tratar de uma bacia com rios de primeira e segunda ordem onde se concentram as nascentes e um volume de água relativamente baixo, torna-se imprescindível também uma análise do grau de preservação das Áreas de Preservação Permanente (APPs) na Alta Bacia do Santo Inácio.

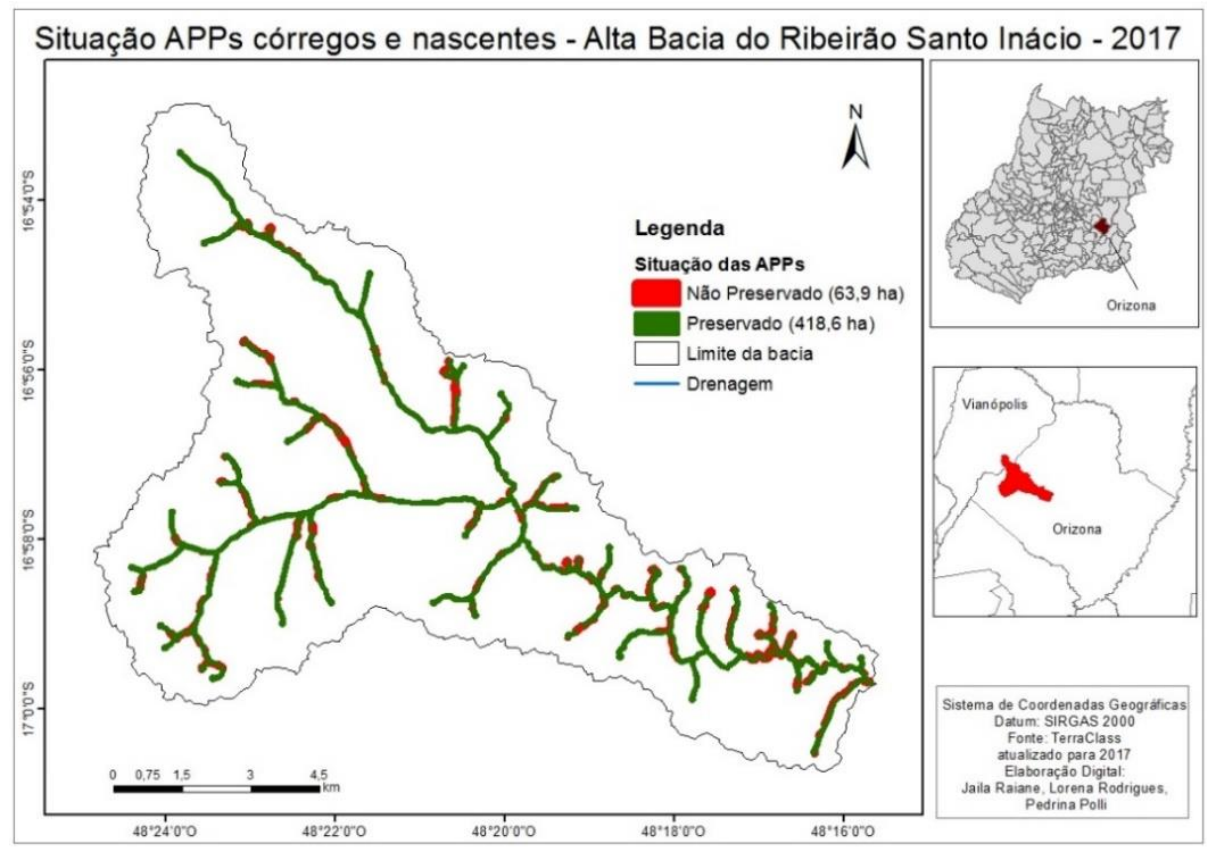

Figura 05: Situação da cobertura vegetal das APPs dos córregos e das nascentes.

Segundo Almeida (2018), além de proteger as matas ciliares, as APPs cumprem a função de proteger os rios e reservatórios de assoreamentos (perda de solos por erosão e consequente acúmulo de sedimentos na bacia) preservando a estabilidade do regime fluvial. Além do mais, a sua inexistência viabiliza o transporte de substâncias poluidoras que após o desflorestamento nessas áreas, podem conduzir à contaminação das águas por defensivos agrícolas utilizados no manejo das lavouras através do escoamento superficial. O que torna ainda mais preocupante quando se observa que a expansão e a modernização da agricultura brasileira têm sido acompanhadas por uma intensificação no uso de fertilizantes. Entre 2009 e 2014, a comercialização de fertilizantes no Brasil cresceu 20,3\%, enquanto a área plantada total cresceu 11,8\% (ANA, 2017b). 
Identifica-se que as maiores partes das áreas não preservadas se encontram ocupadas por áreas de pastagens e pelas barragens de captação para irrigação de pivô central. As APPs avaliadas ao longo dos cursos d'água da Alta Bacia do Ribeirão Santo Inácio totalizaram 482,5 ha que, segundo prevê o Código Florestal Brasileiro, deve ser mantida intacta (Figura 5). A recomposição da mata ciliar atendendo à legislação ambiental, é de 63,9 há, ou seja, cerca de 13,2 \% das APPs não estão preservadas.

Souza et al. (2012) citam que as alterações na vegetação ao longo dos rios, por menor que sejam, criam instabilidade nas zonas ripárias com consequências sobre toda a estrutura hídrica - levando em consideração que os maiores rios são a junção de afluentes formados por rios menores - bem como a vegetação ao redor das nascentes, que são elementos hidrológicos de importância primária para a dinâmica fluvial, pois marcam a passagem da água subterrânea para a superfície pela exfiltração. A destruição da cobertura vegetal implica na diminuição da vazão das nascentes, em médio e em longo prazo, acarretando consequentemente a eliminação gradativa dos rios alimentados por essa nascente.

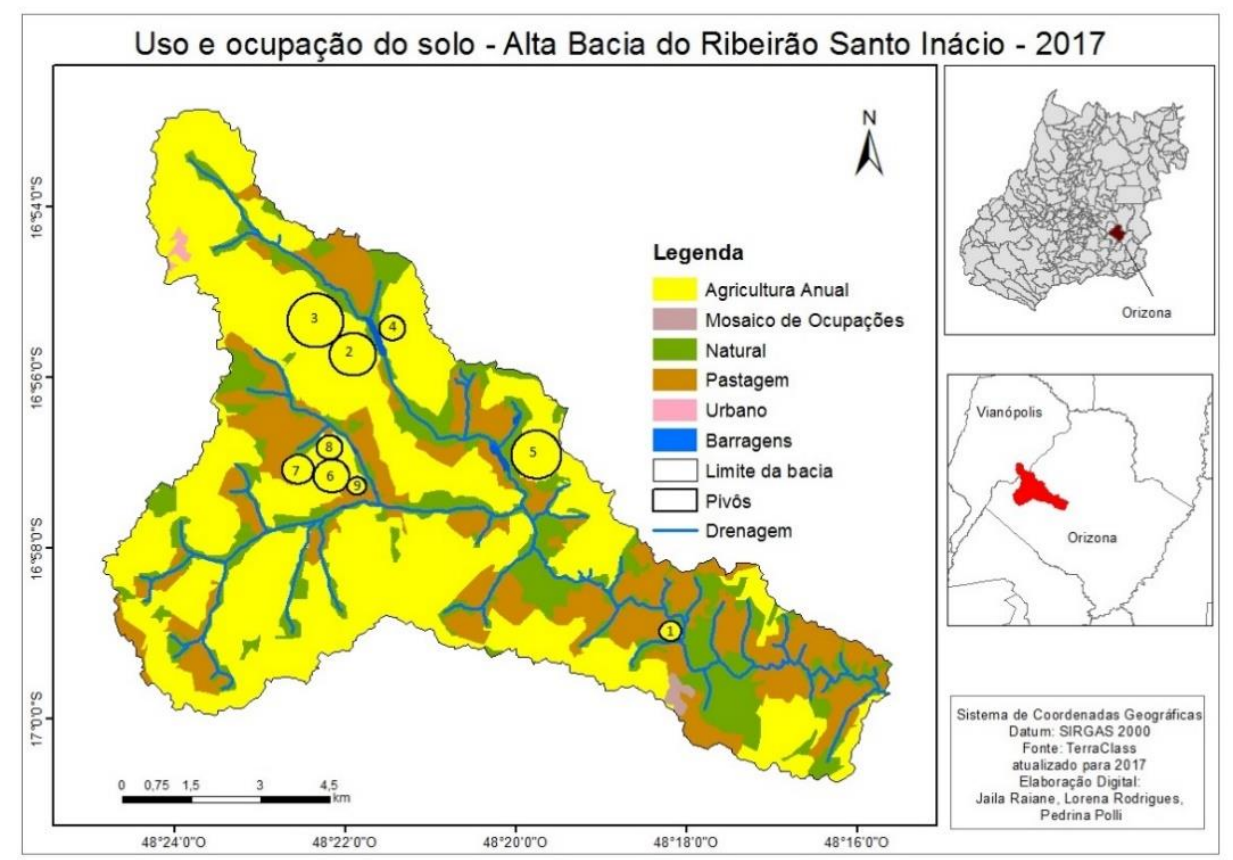

Figura 06: Mapa de uso e ocupação do solo na Alta Bacia do Ribeirão Santo Inácio.

O estudo de uso e ocupação do solo da Alta Bacia do Ribeirão Santo Inácio identificou (6) seis usos e ocupação, nesta área, sendo eles: agricultura, pastagens, natural ou vegetação nativa, urbano, mosaico de ocupação (áreas industriais) e 
barragens, além da hidrografia e da enumeração dos pivôs-centrais, que também foram identificados para melhor compreensão deste estudo.

Aos analisarmos o uso do solo na microbacia, $56,1 \%$ do seu uso é direcionado a agricultura de sequeiro e agricultura irrigada. As áreas de pastagem compreendem $21,6 \%$ da área total sendo este valor a porcentagem de vegetação nativa presente nesta bacia, a área urbana e os mosaicos de ocupações representam $0,5 \%$ vistos na tabela 02 .

Tabela 02: Estatísticas de uso e cobertura do solo na área de estudo.

\begin{tabular}{c|c|c}
\hline Uso e Ocupação & Área (há) & $\begin{array}{c}\text { Porcentagem da área da bacia } \\
(\mathbf{\%})\end{array}$ \\
\hline Agricultura & $5.374,6$ & $56,1 \%$ \\
\hline Água & 21,0 & $0,2 \%$ \\
\hline Pastagem & $2.065,7$ & $21,6 \%$ \\
\hline Mosaico de Ocupações & 28,9 & $0,3 \%$ \\
\hline Vegetação Nativa & $2.066,0$ & $21,6 \%$ \\
\hline Área Urbana & 19,6 & $0,2 \%$ \\
\hline Total & $9.575,8$ & $100,0 \%$ \\
\hline
\end{tabular}

Fonte: elaborado pelos autores com base em dados do satélite TerraClass.

A área industrial é representada pela área urbana e um distrito do município é representado pelo mosaico de ocupações.

\section{A demanda hídrica por pivô central e agroindústria}

Segundo a FAO (2018), a necessidade de água das culturas depende principalmente do clima (em um clima ensolarado e quente, as culturas precisam de mais água por dia do que em um clima nublado e fresco); o tipo de cultura e o estágio de crescimento da cultura. "Durante o período de crescimento, os valores de coeficiente de cultura começam baixos e aumentam à medida que a cobertura se desenvolve até que começam a diminuir com o início da senescência das culturas" (conforme exemplo do quadro 01).

Nos meses de verão, período chuvoso na região Sudeste de Goiás, a precipitação média normalmente supera a demanda da cultura, gerando um excedente de água, que é infiltrada ao solo/lençol freático, ou escorre superficialmente no solo em direção aos cursos hídricos, não sendo necessária a irrigação. O inverso ocorre nos meses secos do ano, onde existe demanda de água para irrigação. 
Quadro 01: Projeção do consumo hídrico do pivô-central 2.

\begin{tabular}{|c|c|c|c|c|c|c|c|}
\hline & $\begin{array}{l}\text { ÁREA } \\
\text { (há) }\end{array}$ & Janeiro & Fevereiro & Março & Abril & Maio & Junho \\
\hline Pivô-central 2 & 68 & soja & soja & - & - & tomate & tomate \\
\hline $\begin{array}{l}\text { Evapotranspiração } \\
(\mathrm{mm} / \text { dia })\end{array}$ & - & 6 & 4 & 0 & 0 & 3 & 4 \\
\hline $\begin{array}{l}\text { Evapotranspiração } \\
\text { (mm/mês) }\end{array}$ & - & 186 & 112 & 0 & 0 & 93 & 120 \\
\hline Precipitação (mm/mês) & - & 286,3 & 204,1 & 206,6 & 79,4 & 34 & 7,9 \\
\hline $\begin{array}{l}\text { BALANÇO } \\
\text { HIDROLOGICO } \\
(\mathrm{mm} / \mathrm{mês})\end{array}$ & - & 100,30 & 92,10 & 206,60 & 79,40 & $-59,00$ & $-112,10$ \\
\hline $\begin{array}{l}\text { Demanda água } \\
\left.\text { irrigação ( } \mathrm{m}^{3} / \mathrm{mês}\right)\end{array}$ & - & $68.204,00$ & $62.628,00$ & $140.488,00$ & $53.992,00$ & $-40.120,00$ & $-76.228,00$ \\
\hline $\begin{array}{l}\text { Perdas do sistema de } \\
\left.\text { irrigação ( } \mathrm{m}^{3} / \mathrm{mês}\right)\end{array}$ & $30 \%$ & 0,00 & 0,00 & 0,00 & 0,00 & $-12.036,00$ & $-22.868,40$ \\
\hline \multirow[t]{2}{*}{$\begin{array}{l}\text { Total água a ser } \\
\text { captada (m³/mês) }\end{array}$} & $\begin{array}{l}\text { PIVO } \\
2\end{array}$ & $68.204,00$ & $62.628,00$ & $140.488,00$ & $53.992,00$ & $-52.156,00$ & $-99.096,40$ \\
\hline & $\begin{array}{l}\text { ÁREA } \\
\text { (há) }\end{array}$ & Julho & Agosto & Setembro & Outubro & Novembro & Dezembro \\
\hline Pivô-central 2 & 68 & tomate & tomate & tomate & soja & soja & soja \\
\hline $\begin{array}{l}\text { Evapotranspiração } \\
(\mathrm{mm} / \text { dia })\end{array}$ & - & 5 & 6 & 0 & 3 & 5 & 6 \\
\hline $\begin{array}{l}\text { Evapotranspiração } \\
(\mathrm{mm} / \mathrm{mês})\end{array}$ & - & 155 & 186 & 0 & 93 & 150 & 186 \\
\hline Precipitação (mm/mês) & - & 5,6 & 13,9 & 53,2 & 112,3 & 193,9 & 296 \\
\hline $\begin{array}{l}\text { BALANÇO } \\
\text { HIDROLÓGICO } \\
(\mathrm{mm} / \mathrm{mês})\end{array}$ & - & $-149,40$ & $-172,10$ & 53,20 & 19,30 & 43,90 & 110,00 \\
\hline $\begin{array}{l}\text { Demanda água } \\
\text { irrigação (m³/mês) }\end{array}$ & - & $\begin{array}{c}- \\
101.592,00 \\
\end{array}$ & $\begin{array}{c}- \\
117.028,00 \\
\end{array}$ & $36.176,00$ & $13.124,00$ & $29.852,00$ & $74.800,00$ \\
\hline $\begin{array}{l}\text { Perdas do sistema de } \\
\left.\text { irrigação ( } \mathrm{m}^{3} / \mathrm{mês}\right)\end{array}$ & $30 \%$ & $-30.477,60$ & $-35.108,40$ & 0,00 & 0,00 & 0,00 & 0,00 \\
\hline $\begin{array}{l}\text { Total água a ser } \\
\text { captada }\left(\mathrm{m}^{3} / \mathrm{mês}\right)\end{array}$ & $\begin{array}{c}\text { PIVO } \\
2\end{array}$ & $\begin{array}{c}- \\
132.069,60\end{array}$ & $\begin{array}{c}- \\
152.136,40\end{array}$ & $36.176,00$ & $13.124,00$ & $29.852,00$ & $74.800,00$ \\
\hline
\end{tabular}

Fonte: elaborado pelos autores com base em dados de pesquisa de campo / Inmet (2018) / FAO (2018).

Além da demanda hídrica da própria cultura, outro fator que impacta o consumo de água consideravelmente são as perdas pelo sistema de irrigação. Como vemos no quadro 1, no mês de agosto houve uma perda de mais de 35 mil metros cúbicos de água. Se contabilizarmos as perdas de todos os pivôs da microbacia, o número chega a cerca de 660 mil metros cúbicos por ano de perda de água.

Ao todo, são 9 pivôs-centrais que captam água do ribeirão Santo Inácio e apenas os pivôs-centrais 2,4 e 5 possuem barragem, o restante realizam a captação direta dos rios. 


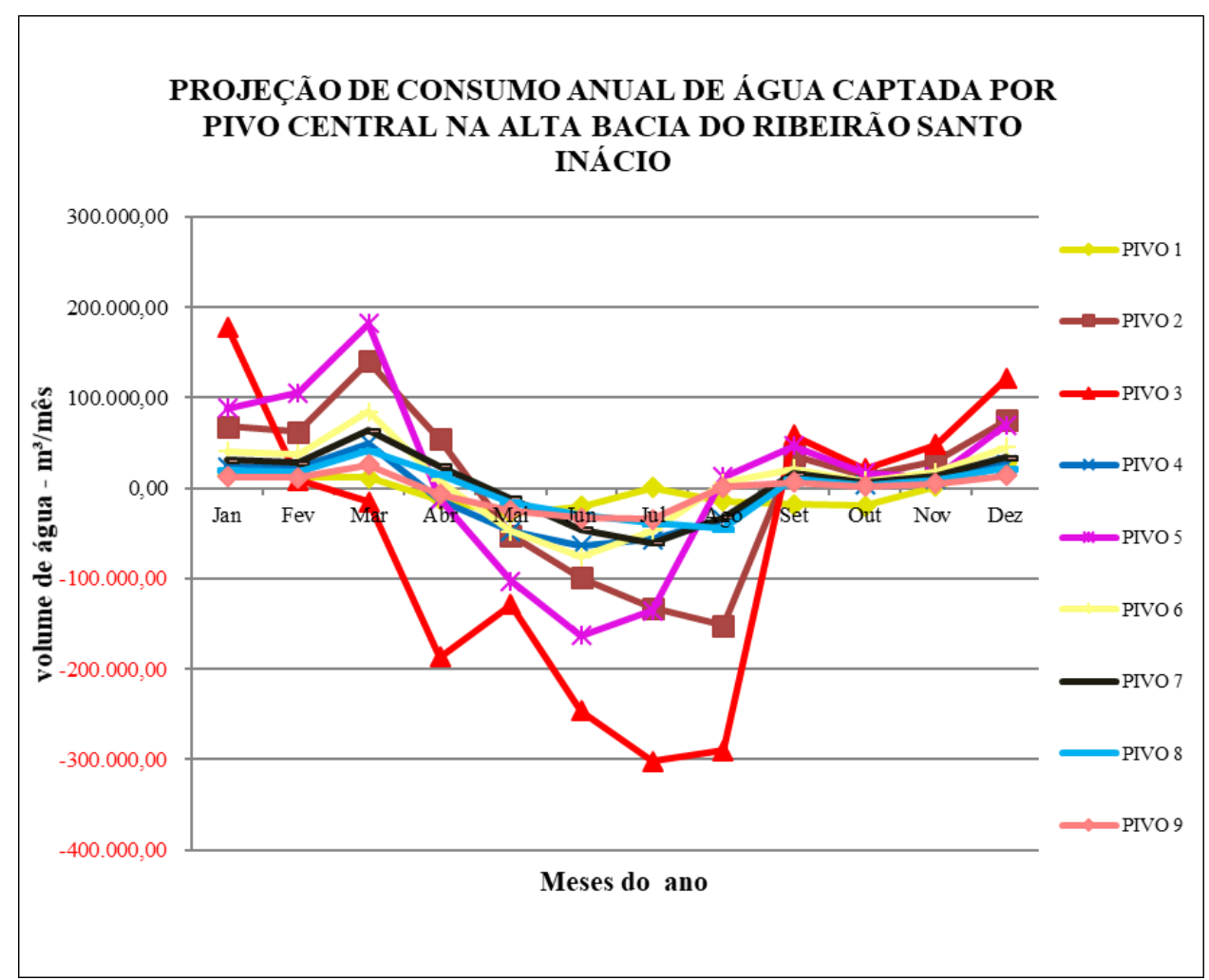

Figura 07: Projeção de consumo hídrico anual captado no Ribeirão Santo Inácio.

Fonte: elaborado pelos autores com base em dados de pesquisa de campo / Inmet (2018) / FAO (2018).

Conforme a projeção do consumo hídrico, o pivô-central 1 entre os meses de abril a outubro houve um déficit hídrico no total de $111.984,6 \mathrm{~m}^{3}$, tendo seu ápice no mês de maio com uma demanda de irrigação de $21.280 \mathrm{~m}^{3}$ e uma média de precipitação de apenas $34 \mathrm{~mm}$.

O déficit hídrico do pivô-central 2 e do pivô-central 9 está entre os meses de maio a agosto, em que há o plantio de tomate industrial numa área de 68 hectares - em agosto, mês de maior déficit hídrico, foram necessários $152.308,5 \mathrm{~m}^{3}$ para irrigar as áreas considerando que choveu apenas $13,9 \mathrm{~mm}$ neste mês - e 20 hectares respectivamente.

O pivô-central 3 é o maior em área, com 110 hectares, tendo como principal cultura plantada o milho doce. A demanda para irrigação no mês de julho chegou a $302.302 \mathrm{~m}^{3}$ considerando que choveu apenas $5,6 \mathrm{~mm}$ nesse mês. O pivô 9 também possui plantio de milho doce nos períodos de estiagem, com períodos de déficit hídrico de abril a agosto chegando a captar $34.352,5 \mathrm{~m}^{3}$ no mês de julho. Os demais pivôs que 
possuem plantio de culturas que variam do feijão ao coentro, também apresentam déficit hídrico significativo no período de estiagem, conforme ilustra a figura 7.

No mês de março o pivô-central 5 possui excedente hídrico de $181.808 \mathrm{~m}^{3}$ considerando somente a precipitação total - devido o intervalo de plantio de uma cultura para outra.

A partir da avaliação da disponibilidade de recursos hídricos no período de estiagem (característica típica do clima tropical, geralmente abrangendo os meses de junho a setembro), observa-se que a demanda pela água é maior devido às baixas precipitações que não são o suficiente para abastecer as barragens de irrigação agrícola e por ser o período de maior produção das indústrias, momento este em que aumenta a quantidade de matéria-prima processada.

As principais culturas plantadas são o milho doce e o tomate industrial e parte da produção anual é direcionada as agroindústrias.

Como podemos observar na figura 08 , o período considerado crítico pela falta de precipitação na região é também o período de maior consumo de água pela indústria B. Considerado o período de safra de colheita de tomate, a indústria aumenta cerca de três vezes mais a sua capacidade industrial chegando a captar mais de 100 mil metros cúbicos por mês entre os meses de agosto e outubro.

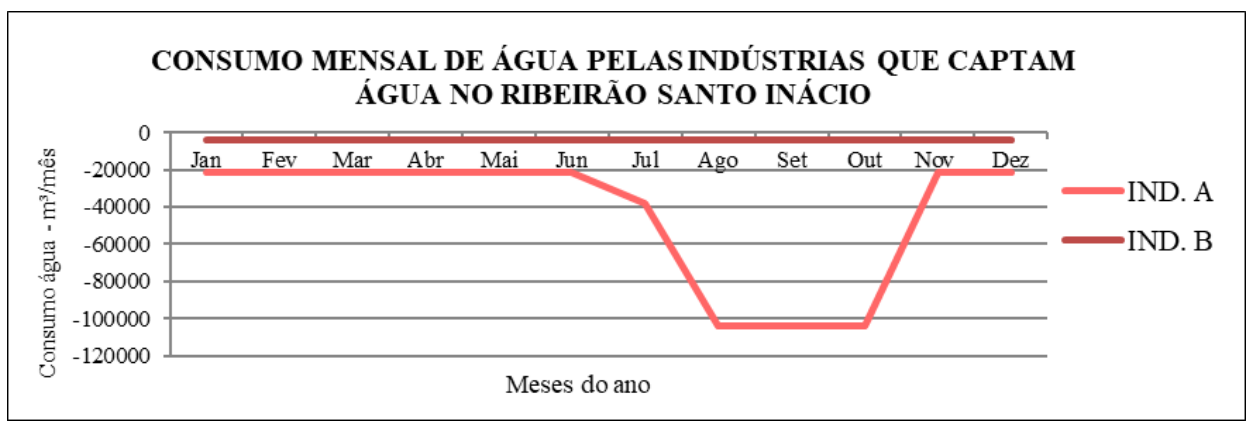

Figura 08: Consumo hídrico anual por indústrias no Ribeirão Santo Inácio.

Fonte: Agristar do Brasil e Conservas Oderich (2018).

Já a indústria A possui um consumo anual constante de cerca de 3.800 metros cúbicos ao mês, uma captação de água menor em relação a indústria $\mathrm{B}$ por se tratar de produção de sementes de hortaliças, flores e ervas, não apresentando período de safra.

Ao relacionar os dados da figura 7 com os dados da figura 8, podemos observar que o período de maior captação de água pelos pivôs-centrais é também o maior período de captação de água pela indústria A. Por conseguinte, a produção dos pivôs é direcionada a produção e processamento na respectiva indústria, o que causa uma dependência mútua para ambos serem beneficiados. Porém, conforme mostra a figura 9 , 
a captação total de água no período de estiagem chega a mais de 812 mil metros cúbicos por mês, ou seja, cerca de 303 litros por segundo.

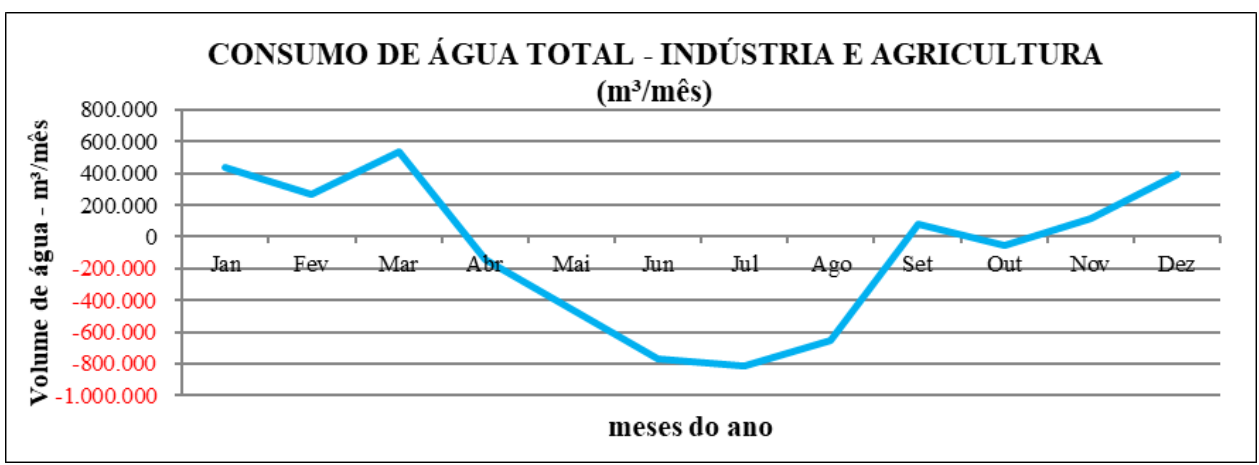

Figura 9: Volume total anual de água captada no Ribeirão Santo Inácio.

Fonte: elaborado pelos autores.

Segundo a Secretaria do Meio Ambiente, Recursos Hídricos, Infraestrutura, Cidades e Assuntos Metropolitanos do estado de Goiás (2018), todos os pivôs centrais da Alta Bacia do Ribeirão Santo Inácio possuem outorga de direito de uso da água.

\section{Considerações finais}

As características físicas associadas aos fatores históricos de ocupação e desenvolvimento territorial do Sudeste de Goiás fazem com que a Alta Bacia do Ribeirão Santo Inácio seja uma área de forte influência da agropecuária. A água é o principal suporte para a produção da crescente demanda de alimentos no Brasil e no mundo e ao mesmo tempo, é um recurso basilar a manutenção da biodiversidade.

Com uma área majoritariamente composta por latossolos e por relevo plano o agrohidronegócio se faz presente, uma vez que há indústrias receptoras dessa produção nas proximidades. Porém, com o crescente número de pivôs centrais, mesmo com as barragens para conter a água, no período de estiagem os rios não conseguem fornecer água suficiente para suprir os usos múltiplos da respectiva microbacia.

A Alta Bacia do Ribeirão Santo Inácio apresenta 78,2\% de sua área total coberta por usos antrópicos, sendo a agricultura o uso predominante, com 56,1\%. Cerca de 13,2\% das áreas de preservação permanente encontram-se degradadas, o que potencializa a deterioração das nascentes e o escoamento superficial de defensivos agrícolas até o curso d'água.

A partir da análise dos parâmetros físicos e da captação de água por pivôs centrais e pela indústria na Alta Bacia do Ribeirão Santo Inácio, soluções e alternativas para minimizar os impactos ambientais e a utilização da água de forma rentável e sustentável mostram-se necessárias, afim de evitar maiores desperdícios, preservar as 
áreas de APPs instituídas por lei e consequentemente evitar maiores conflitos pelos usuários de água local.

Ademais, o argumento de que a produção de alimentos é uma necessidade para suprir as demandas de uma população crescente, reivindicam mais investimentos para ampliar a área irrigada, sob o pretexto de que há ainda no Brasil um enorme potencial hídrico a ser explorado.

Se torna urgente e necessária a gestão integrada das águas e a análise de bacias hidrográficas das mais diversas regiões do Brasil, para auxiliar através de técnicas (a exemplo do mapeamento geográfico) a otimização de planos de gerenciamento para o uso sustentável da água, a fim de conciliar suas diversas destinações na sociedade sem comprometer sua qualidade e seu ciclo hidrológico natural.

\section{Referências bibliográficas}

ANA (Agência Nacional das Águas). Conjuntura dos recursos hídricos no Brasil. Brasília: ANA, 2017a.

ANA (Agência Nacional das Águas). Atlas irrigação: uso da água na agricultura irrigada. Brasília: ANA, 2017b.

BOUGUERRA, M. L. As batalhas da água: por um bem comum da humanidade. Petrópolis: Editora Vozes, 2004.

COOLEY, L. As funções do conflito social. Trad. Hergett, C. São Paulo, DC, n. 54, 1984.

EMBRAPA (Empresa Brasileira de Pesquisa Agropecuária). Manejo integrado de bacias hidrográficas. Sete Lagoas: Embrapa Milho e Sorgo, 2003.

Embrapa. Sistema Brasileiro de Classificação de Solos. Disponível em:

<https://www.agrolink.com.br/downloads/sistema-brasileiro-de-classificacao-dossolos2006.pdf> Acesso em: 17 fev. 2019.

FAO. Single crop coeficiente. Disponível em:

<http://www.fao.org/docrep/x0490e/x0490e0b.htm\#tabulated kc values> Acesso em: 14 fev 2018.

GOMES, A. S. et al. A água: distribuição, regulamentação e uso na agricultura, com ênfase ao arroz irrigado. Disponível em <

https://www.agencia.cnptia.embrapa.br/Repositorio/documento_250_000fxizbmhw02wy iv80soht9hixxd8a1.pdf> Acesso em: 05 mai. 2019.

INMET (Instituto Nacional de Meteorologia). Dados meteorológicos de estações automáticas. Disponível em:

<http://www.inmet.gov.br/portal/index.php?r=estacoes/estacoesAutomaticas> Acesso em: 13 mai 2018. 
IMB (Instituo Mauro Borges). Mapeamento dos pivôs centrais instalados no Estado de Goiás e no Distrito Federal no ano de 2016. Atualização da autora para o ano de 2017. Disponível em: <http://www.sieg.go.gov.br/produtosIMB.asp?cod=4712> Acesso em: $01 \mathrm{dez} 2018$.

FREITAS, E. P. et al. Indicadores ambientais para áreas de preservação permanente. Revista Brasileira de Engenharia Agrícola e Ambiental: 2013. v.17, n.4, p. 443-449.

LIMA, Walter de Paula. Hidrologia florestal aplicada ao manejo de bacias hidrográficas. Piracicaba: Universidade de São Paulo, 2008.

MARTINS, R. A. O agrohidronegocio do pivo central no estado de goias: expansão, espacialização e a consequente degradação do subsistema de veredas. Tese (Doutorado em Geografia) - Instituto de Ciências Humanas, Universidade Brasília. Brasília, 2017.

MAROUELLI, W. A. et al. Manejo da água de irrigação. In: SOUSA, V. F. et al. (Ed.). Irrigação e fertirrigação em fruteiras e hortaliças. Brasília: EMBRAPA, 2011. p. 157232.

MENDONÇA, M. R. Complexidade do espaço agrário brasileiro: O agrohidronegócio e as (re)existências dos povos Cerradeiros. Terra Livre, São Paulo, ano 26, v. 1, n. 34, p. 189-202, jan./jun. 2010.

OLIVEIRA, D. A.; ASSUNÇÃO, W. L. O uso da água e do solo da bacia hidrográfica do córrego lajeado, Araguari-MG. Caminhos de Geografia, Uberlândia, v. 14, n. 46, p. 204-219, jun 2013.

RAMALHO FILHO, A; BEEK, K. L. Sistema de avaliação da aptidão agrícola das terras. $3^{\text {a }}$ ed. Rio de Janeiro. EMBRAPA, CNPS, 1995.

SANTOS, R. F. CARLESSO, R. Déficit hídrico e os processos morfologico e fisiologico das plantas. Revista Brasileira de engenharia agricola e ambiental. Campina Grande, v.2, n.3, p.287-294, 1998.

SOUZA, S. R. et al. Caracterização do conflito de uso e ocupação do solo nas áreas de preservação permanente do Rio Apeú, nordeste do Pará. Revista Floresta: 2012. v.42, p. 705.

POLETO, C. Bacias hidrográficas e recursos hídricos. Rio de Janeiro: Interciência, 2014.

TEODORO, V. L. I. et al. O conceito de bacia hidrográfica e a importância da caracterização morfométrica para o entendimento da dinâmica local. Revista Uniara: 2007. N. 20. 


\section{Lorena de Castro Rodrigues}

Géografa formada pela Universidade Federal de Goiás, onde desenvolve pesquisas junto ao Laboratório de Geomorfologia, Pedologia e Geografia Física (Labogef).

Rua 262, Leste Universitário Cep: 74615-300, Goiânia/GO.

Email: rodrigues.lorenac@gmail.com

\section{Maximiliano Bayer}

Geólogo formado pela Universidad Nacional de San Luis - Argentina. Mestrado em Geografia pela Universidade Federal de Goiás.

Doutor em Ciências Ambientais CIAMB-UFG.

Professor adjunto do Instituto de Estudos Socioambientais - UFG.

Instituto de Estudos Socioambientais - IESA, Campus Samambaia, Conjunto Itatiaia, Caixa Postal 131, Cep: 74001-970 - Goiânia/GO.

Email: maxibayer@yahoo.com.ar

Recebido para publicação em dezembro de 2018 Aprovado para publicação em março de 2019 